\title{
Laboratory tests of soft ground improvement with drained-timber pile:A new timber pile technique
}

\author{
Limin $\mathrm{Wu}^{1, \mathrm{a}}$, Xinjun Chai ${ }^{\star 1,}$, Yifan Xiong ${ }^{1, a}$, and Peng Zhou ${ }^{1, a}$ \\ ${ }^{1}$ School of Civil \& Architecture Engineering, East China University of Technology, China \\ axj_chai@126.com
}

\begin{abstract}
Keywords: Soft clay, ground imporvement, drained-timber pile, soil-column, consolidation Abstract. In modern times, with the rise of high buildings, the timber piles were replaced by steel piles, precast concrete piles and various composition foundation, the main reason is that the soft ground improved with timber piles has the weakness of low bearing capacity and large post construction settlement. To overcome the weakness of the traditional pine-pile technology and expand its application in engineering practice, the drained-timber pile: A new timber pile technology was developed. To verify the feasiblity and evaluated the effectiveness of the drained-timber pile technology, four types of laboratory soil-column consolidation tests were performed. The test results revealed that under the same loading and consolidation time, the radial consolidation of the drained-timber rod has a domiant contribution to the total degree of consolidation, the drained geotextle layer of drained-timber rod can obviously increase the degree of consolidation comparing with traditional timber rod. It can be expected that the new timber pile technique has a good application prospect in soft ground improvement for medium-small size hydraulic structures.
\end{abstract}

\section{Research background}

Pine pile is an ancient technology applied in soft ground improvement for more than 1000 years. For example, Hayashi reported that even after more than one thousand years, wood reinforcement under the Mizuki embankment in North Kyushu, Japan still has high durability in an under water-table condition [1]; It was reported that the soft clay foundation of the ancient Water-Gate site of the Southern Taizhou (Jiangsu province, China) was reinforced with timber piles, which still remains a relatively complete state more than one thousand years at underground water condition [2]. Many ancient ruins were excavated and it was found that the pine piles were still remained in good status, which verified that the pine piles have good durability and strong corrosion resistance under water condition.

Yet, it can not be concluded that timber pile technique has disappeared in soft ground improvement. On the contrary, in some special conditions, timber piles have a certain advantages comparing with concrete piles, steel piles et al. For example, timber-piles are widely employed in small-medium size hydraulic structure engineerings in the regions with rich pine resources [3-5]. Especially, in recent years, with the enhancement of environmental protection and resource protection consciousness, the timber pile has been attracting the attention of the engineers and researchers due to its environment-friendly characteristics, obvious economic benefits and suitability[6,7].

However, the traditional timber pile technique has the following two disadvertages while applied to improve soft ground, one is that: 1) the low bearing capacity of timber pile due to the low shear strength of the soft clay restrict the height of the superstructures; another is that 2) the large post-construction settlement due to the low permeability of the soft clay frequently lead to cracking of superstructures. The above two problems restrict the extensive application of timber-pile composite foundation for buildings in soft soil area.

To overcome the weakness of the traditional timber pile technology, the drained-timber pile technique was developed by the research group [8,9]. In the study, a special laboratory soil-column apparatus was designed to perform consolidation tests for drained-timber rods. Totally, four types of soil-column consolidation tests were carried out to investigate the feasibility and efficiency of the drained-timber pile technique. The test results revealed that the drained-timber rod can obviously 
Table 1 Physical properties of the mucky clay used in the test

\begin{tabular}{|c|c|c|c|c|c|c|c|}
\hline Term & $\begin{array}{c}\text { Natural } \\
\text { density } \\
\rho \\
\left(\mathrm{g} / \mathrm{cm}^{3}\right)\end{array}$ & $\begin{array}{c}\text { Water } \\
\text { content } \\
\omega \\
(\%)\end{array}$ & $\begin{array}{c}\text { Specific } \\
\text { gravity } \\
G_{s}\end{array}$ & $\begin{array}{l}\text { Plastic } \\
\text { limit } \\
\text { PL }\end{array}$ & $\begin{array}{c}\text { Liquid } \\
\text { limit } \\
\text { LL }\end{array}$ & $\begin{array}{l}\text { Plasticity } \\
\text { Index } \\
\text { PI }\end{array}$ & $\begin{array}{l}\text { Liquidity } \\
\text { Index } \\
\text { LI }\end{array}$ \\
\hline Quatity & 1.74 & 90.26 & 2.67 & 26.0 & 52.2 & 26 & 2.47 \\
\hline
\end{tabular}

Table 2 Set up of soil-column consolidation tests with (drained)-timber rods

\begin{tabular}{cccccccc}
\hline $\begin{array}{c}\text { Type } \\
\text { of } \\
\text { Tests }\end{array}$ & $\begin{array}{c}\text { Diamete } \\
\text { r of rod } \\
(\mathrm{mm})\end{array}$ & $\begin{array}{c}\text { Drained } \\
\text { geotextile }\end{array}$ & $\begin{array}{c}\text { Length of } \\
\text { embedded rod } \\
(\mathrm{mm})\end{array}$ & $\begin{array}{c}\text { Drained } \\
\text { geotextile }\end{array}$ & $\begin{array}{c}\text { Height of } \\
\text { soil column } \\
(\mathrm{mm})\end{array}$ & $\begin{array}{c}\text { Vertical } \\
\text { drain }\end{array}$ & $\begin{array}{c}\text { Radial } \\
\text { drain }\end{array}$ \\
\hline L1 & No & No & No & No & 100 & $\sqrt{ }$ & --- \\
L2 & 10 & No & 100 & No & 100 & $\sqrt{ }$ & --- \\
L3 & 10 & 2 layers & 100 & 2 layers & 100 & -- & $\sqrt{ }$ \\
S0 & 10 & 2 layers & 100 & 2 layers & 100 & $\sqrt{ }$ & $\sqrt{ }$ \\
\hline
\end{tabular}

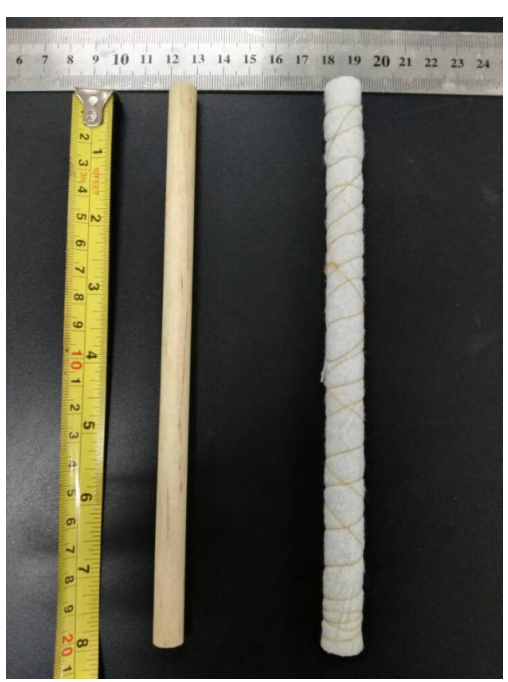

Fig.1 Photos of timber rod and drained-timber rod for wooden rod with diameter of $10 \mathrm{~mm}$

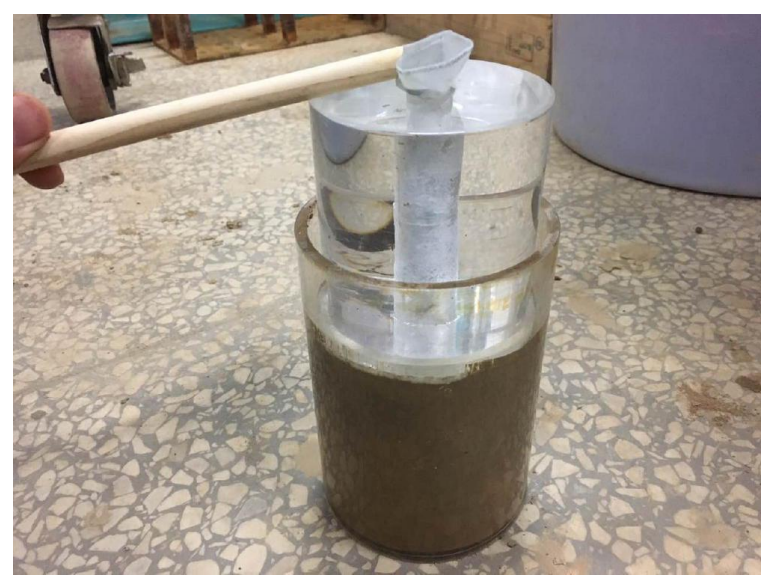

Fig.2 Set up of soil-column with (drained)-timber bolt before loading

increase the degree of consolidation comparing with traditional timber rod. It can be expected that the drained-timber pile technique has a good application prospect for the medium-small hydraulic engineering structures and pretreatment of super soft foundation in the pine rich area.

\section{Test Schematic Design}

Soil Preparation. The soil tested was collected from Diezi Lake of Nanchang city, Jiangxi Province. The main physical and mechanical properties of the soil were listed in Table 1, the soil is a typical soft clay in the Poyang Lake region.

Drainage Geotextile. The drained geotextile is the main composition of the drained-timber pile, a non-woven geotextile, which is made of $150 \mathrm{~A}$ by the factory with the quality of $150 \mathrm{~g} / \mathrm{cm}^{3}$ and thickness of $1.0 \mathrm{~mm}$, was employed as the drained layer of the drained-timber rod. The permeability coefficient of the geotexitle is about $1 \times 10^{-1} \mathrm{~cm} / \mathrm{s}$.

Preparation of timber rod and drained-timber rod. In the experiment, the timber rod is made from the pine rod with a diameter of $10 \mathrm{~mm}$. The drained-timber rod is made up of a timber bolt (diameter 
$10 \mathrm{~mm}$ ) with 2 layers of drainage geotextile wrapped around the timber bolt. The timber rod and the drained-timber rod are shown in Fig.1

Model Design of Laboratory Soil-Column Consolidation Test. The laboratory soil-column model was composed of plexiglass cylinder, pressure plate, plexiglass hollow transfer column, loading and data monitoring recording system, the details of the soil-column apparatus can be referred in the reference $[8,9]$.

Design of Four Types of Laboratory Column Consolidation Tests. In order to verify the drainage consolidation performance of the drained-timber rod, a total of four types of soil-column consolidation tests were designed, as listed in Table 2. In all the tests, the initial height of the soil column was set as $100 \mathrm{~mm}$, and the total length of the (drained) timber rod was $150 \mathrm{~mm}$, and the embedded length in soil of the rod was $100 \mathrm{~mm}$.

Test L1 is just soil column without (drained) timber rod at vertical upward drainage condition; test L2 is soil column with just timber rod at vertical upward drainage condition; test L3 is soil column with drained-timber rod at radial drainage condition, the top boundary of the soil column was sealed with a thin geomembrane; test S0 is soil column with drained-timber rod at both vertical upward drainage and radial drainage condition, test S0 is designed as the basic standard tests for drained-timber rod.

\section{Test Procedures}

Sample Preparation.The test samples were prepared with initial moisture content of $90 \%$ and 100 $\mathrm{mm}$ in height, the photo of the soil-column consolidation sample before loading is shown in Fig. 2. (Note:for test L3, a piece of impermeable geomembrane pad is used to take the place of the permeable geotextile to achieve the only radial drainage condition).

Loading Scheme. The loading scheme is designed as 6 steps, which are $6.25 \mathrm{kPa}, 12.50 \mathrm{kPa}, 25 \mathrm{kPa}$, $50 \mathrm{kPa}, 100 \mathrm{kPa}, 200 \mathrm{kPa}$, respectively; each loading step is maintained for 24 hours.

\section{Analysis and Discussion of the Test Results}

Relationship Between the Consolidation Settlement and Time.The relationships of the consolidation settlement with time of the four types of tests are plotted in Fig.3 to Fig.6.

Compring Fig. 3 and Fig.4, it indicates that the final settlements are $32.60 \mathrm{~mm}$ and $32.70 \mathrm{~mm}$ for the test L1 and test L2, respectively, the curves of settlement with time under each step loading are almost close to agreement. It means that the traditional timber-rod is impermeable and has little contribution to increasing the consolidation degree of soft clay, this is a reasonable results and agree with theoretical speculation.

Comparing Fig. 4 and Fig.6, it indicates that the final settlements are $32.70 \mathrm{~mm}$ and $36.85 \mathrm{~mm}$ for test L2 and test S0, respectively. For test L2 and S0, the only difference is that test S0 use drained-timber rod and L2 use timber rod, it reveals that under the same loading and drained condition, the two geotextile layer of the drained-timber rod can well play the role of radial drainage and contribute a lot to the total consolidation degree.

Comparing Fig.5 and Fig.6, it indicates that the final settlements are $36.50 \mathrm{~mm}$ and $26.85 \mathrm{~mm}$ fore test L3 and test S0, respectively, the curves of settlement with time for tests L3 and S0 under each step loading are almost close to agreement. It means that for the drained-timber rods, with two drained layers of geotextile, the radial drainage has a dominant contribution to the total consolidation degree, and the vertical drainage has little contribution to the total consolidation degree, the phenomenon reveals that the two thin layers of geotextile is quite effective for increasing the radial consolidation; Relationship of Void Ratio to Consolidation Pressure. The relations of the void ratio vs. consolidation pressure of four types of tests are plotted in Fig.7. Figure 7 indicates that, under the same load increment and the same consolidation time ( 24 hours), the increments of consolidation settlement of tests L3 and S0 are always greater than that of the Tests L1 and L2, which reveals that the drainage layer structure of the drained-timber rods can effectively improve the consolidation degree of soft clay. 


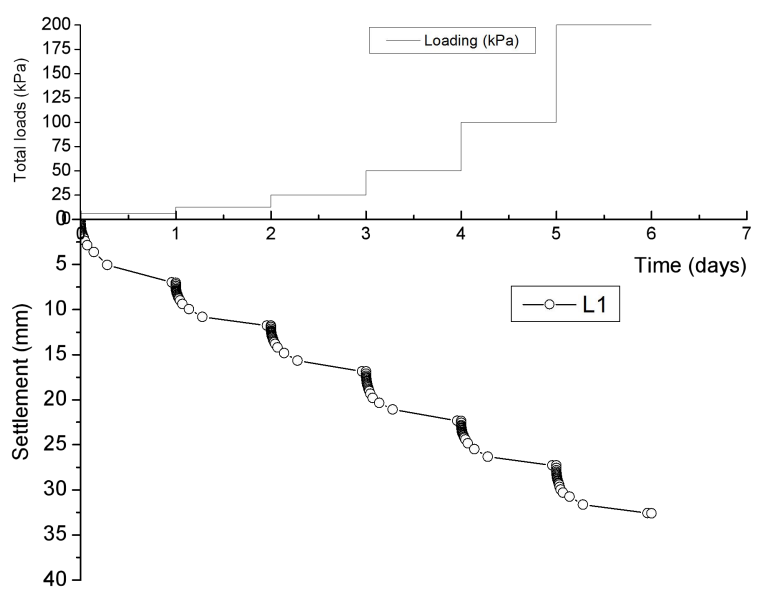

Fig.3 Loading and consolidation settlement vs. time for test L1

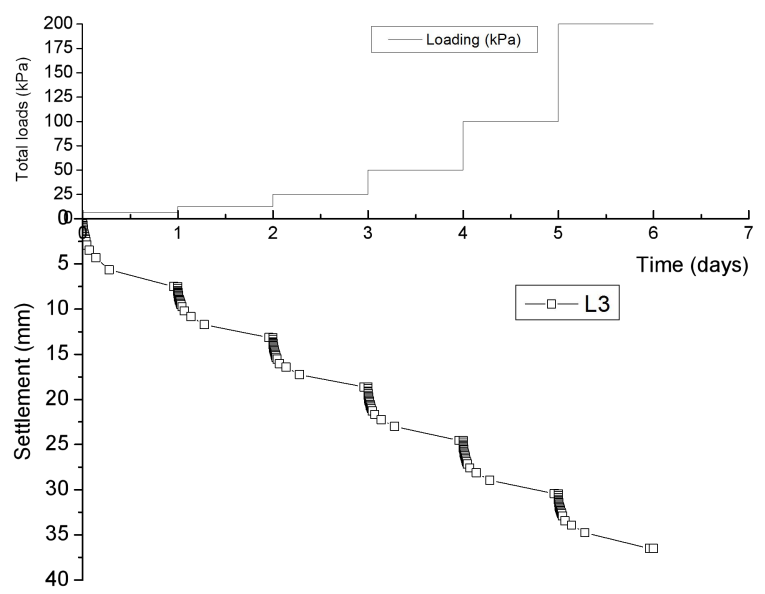

Fig.5 Loading and consolidation settlement vs. time for test L3

\section{Conclusions}

Aiming to improve the weakness of the traditional pine pile in reinforcing soft clay foundation, the drained-timber pile was developed. Four types of laboratory model tests were carried out to evaluate the effectiveness of the drained-timber pile, the conclusions are made as follows: 1) the traditional timber-rod is impermeable and has little contribution to increasing the consolidation degree of soft clay, this is a reasonable results and agree with theoretical speculation; 2) for the drained-timber rods, with two drained layers of geotextile, the radial drainage has a dominant contribution to the total consolidation degree, and the vertical drainage has little contribution

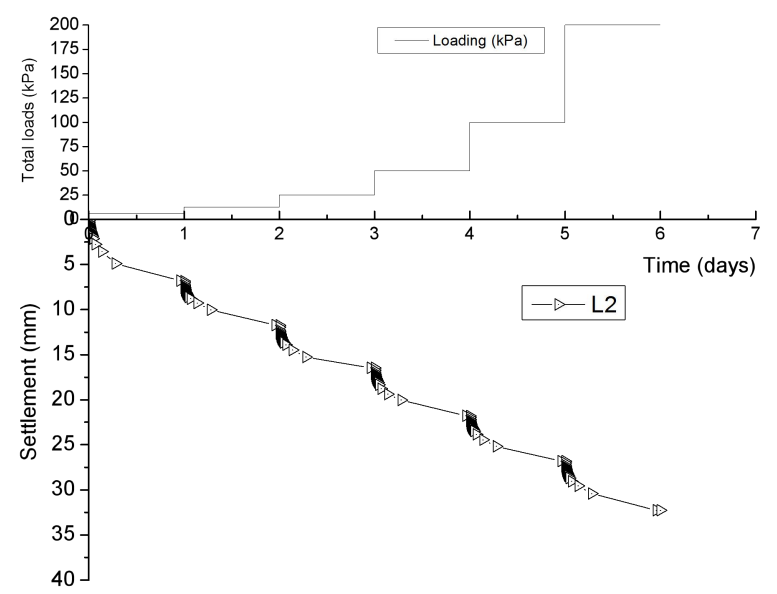

Fig.4 Loading and consolidation settlement vs. time for test L2

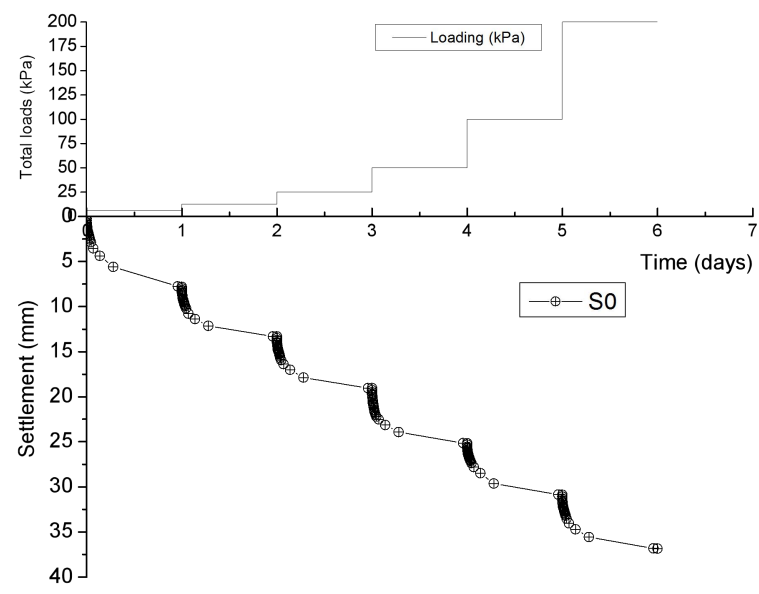

Fig.6 Loading and consolidation settlement vs. time for test $\mathrm{S} 0$

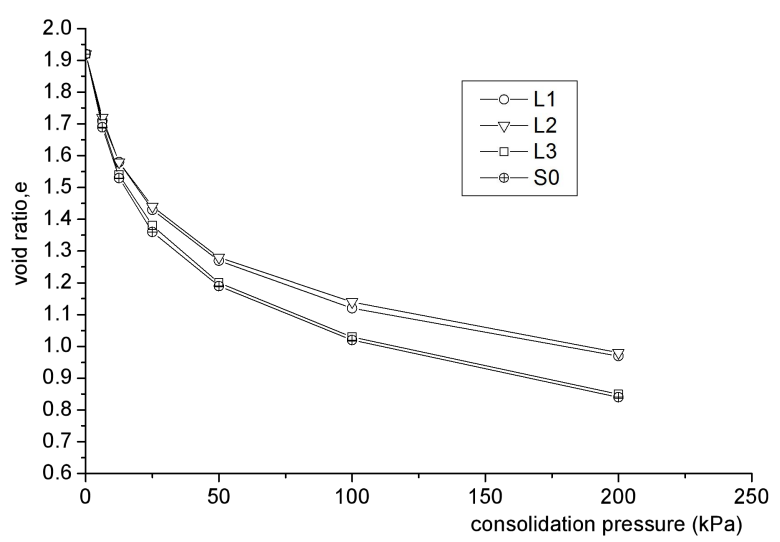

Fig. 7 Curves of void ratio vs. consolidation pressure for the four types of tests 
to the total consolidation degree, the phenomenon reveals that the two thin layers of geotextile is quite effective for increasing the radial consolidation; 3) it is recommended that the effectiveness and contribution of the drained-timber pile should be evaluated further in a more longer soil column model test; 4) it can be expected that the drained-timber pile will have a prosperous application in small-medium size.

\section{Acknowledgements}

The work described in this paper was supported by the National Natural Science Foundation of China (Grant No.51668002, Grant No.51368002, Grant No.50968001), the Natural Science Foundation of Jiangxi Provincial Department of Science and Technology (20151BAB206056), the Science and Technology Support program (20151BBE50014) of Jiangxi Provincial Department of Science and Technology, the Science and Technology project of Jiangxi Provincial Department of Education (GJJ150580), the Graduate Student Innovation Special Fund Project of Jiangxi Province (YC2017-S274).The authors also thank the anonymous reviewers for their comments.

\section{References}

[1] S. Hayashi, and Y.J. Du. Geotechnical analysis of Mizuki embankment remains. Soils and Foundations, 2005,45(6), p.43-53.

[2] Nanjing Museum, Taizhou Museum: Excavation report of the ancient water gate site in southern Taizhou, Jiangsu Province. Southeast Culture, 2014(1), p.43-52.

[3] W. P. Chen. Design and construction of timber piles in soft clay ground. Journal of Guangdong Technical College of Water Resources and Electric Engineering, 2005,3(1), p.49-53 (in Chinese).

[4] S.B. Yu. Application of deal pile foundation in Xishalianwei tide gate. Guangxi water resources and Hydropower Engineering, 2005(2), p.25-27 (in Chinese).

[5] J.H. Ao, H.G. Zhai. Application of timber piles in reinforcing the foundation of retaining wall. City Road and Flood Control, 2009(7), p.231-235 (in chinese).

[6] T. Yang, J. Zhou, C. Zhou. Analysis and design of Timber-pile composite foundation on soft soils. Chinese Journal of Rock Mechanics and Engineering, 2003, 22(9), p.1560-1565.

[7] P. Poungchompu, S. Hayashi, D. Suetsugu, Y.J. Du and M.C Alfro. Performance of Raft \& Pile foundation on soft Ariake clay ground under embankment loading. Lowland Technology International, 2010, 12(1), p.41-46.

[8] Y.F. Xiong. The indoor columnar model experiment on flexibility drainage pile piles reinforcement soft soil foundation. The master degree thesis, East China University of Technology, Nanchang, Jiangxi Province, 2016, China.

[9] X.J. Chai, C.F. He, Y.F. Xiong, L.M. Wu, P. Zhou. Laboratory model tests on drainage consolidation performance of drained-timber pile. Proc. The 2017 3rd International Conference on Civil, Hydraulic and Environmental Engineering. Nov.25-26, 2017, Shenzhen, China (in press). 